\title{
Новые тенденции
}

\section{В ПРОФИЛАКТИКЕ И ЛЕЧЕНИИ ПОСЛЕРОДОВОГО МАСТИТА И ЛАКТОСТАЗА}

\author{
А.А. БАЛУШКИНА ${ }^{1}$, В.Л. ТЮТЮННИК ${ }^{1}$, Н.Е. КАН ${ }^{1}$, О.А. ПУСТОТИНА ${ }^{2}$, Г.В. МОСКАЛЕВА ${ }^{3}$ \\ 1 Федеральное государственное бюджетное учреждение «Национальный медицинский исследовательский центр акушерства, гинеколо- \\ гии и перинатологии имени академика В.И. Кулакова» Министерства здравоохранения Российской Федерации: 117997, Россия, \\ г. Москва, ул. Академика Опарина, д. 4 \\ 2 чоУ ДПО «Академия медицинского образования им. Ф.И. Иноземцева»: Россия, 190013, Санкт-Петербург, Московский пр., д. 22 , литер М. \\ 3 Федеральное государственное бюджетное образовательное учреждение высшего образования «Московский государственный медико- \\ стоматологический университет имени А.И. Евдокимова» Министерства здравоохранения Российской Федерации: 127473, Россия, \\ г. Москва, ул. Делегатская, д. 20, стр. 1
}

\section{Информация об авторах:}

Балушкина Анна Андреевна - К.М.Н., научный сотрудник Федерального государственного бюджетного учреждения «Национальный исследовательский медицинский центр акушерства, гинекологии и перинатологии им. акад. В.И. Кулакова» Минздрава России. 117997, г. Москва ул. Академика Опарина, д. 4; тел.: +7 (916) 035-24-71; e-mail: ann.balushkina@gmail.com. Тютюнник Виктор Леонидович - Д.М.Н., профессор, заведующий 1-м акушерским физиологическим отделением Федерального государственного бюджетного учреждения «Национальный исследовательский медицинский центр акушерства, гинекологии и перинатологии им. акад. В.И. Кулакова»
Минздрава России. 117997, г. Москва, ул. Академика Опарина, д. 4; тел.: +7 (903) 96950-41; e-mail: tioutiounnik@mail.ru.

Кан Наталья Енкыновна - Д.М.н., профессор кафедры акушерства и гинекологии Федерального государственного бюджетного учреждения «Национальный исследовательский медицинский центр акушерства, гинекологии и перинатологии им. акад. В.И. Кулакова» Минздрава России. 117997, г. Москва, ул. Академика Опарина, д. 4; тел.: +7 (926) 220-86-55; e-mail: kan-med@mail.ru.

Пустотина Ольга Анатольевна - д.М.н., профессор кафедры акушерства и гинекологии с курсом репродуктивной медицины, ЧОУ ДПО «Академия медицинского образования им. Ф.И. Иноземцева», Санкт-Петербург. Россия, 190013, Санкт-Петербург, Московский пр., д. 22, литер М; тел.: +7 (812) 334-76-50; e-mail: pustotina@gmail.com. ORCID: 0000-0001-6117-7270

Москалева Галина Владимировна - студентка 6-го курса лечебного факультета Федерального государственного бюджетного образовательного учреждения высшего образования «Московский государственный медико-стоматологический университет имени А.И. Евдокимова» Министерства здравоохранения Российской Федерации: 127473, г. Москва, ул. Делегатская, д. 20, стр. 1; тел.: +7 (903) 623-28-93; e-mail: g_moskaleva@oparina4.ru

\section{PE310ME}

Исключительно грудное вскармливание в первые 6 месяцев жизни рекомендовано ВОЗ, поскольку грудное молоко обеспечивает ребенка всеми питательными веществами и элементами, необходимыми для нормального развития и роста. В первые недели лактации женщины могут особенно часто сталкиваться с рядом проблем, таких как боль в молочных железах и сосках, трещины сосков и мастит. Эти проблемы затрудняют кормление и в некоторых случаях приводят к прекращению грудного вскармливания. Мастит является грозным осложнением послеродового периода и основой причиной прекращения лактации. Консультирование и поддержка матерей, профилактика лактостаза, трещин сосков и обучение техникам правильного прикладывания ребенка приводят к снижению осложнений лактации. Своевременная диагностика и адекватная терапия мастита способствуют сохранению грудного вскармливания и улучшению здоровья матери и ребенка.

Ключевые слова: грудное вскармливание, лактостаз, послеродовый мастит, лактобактерии

Для цитирования: Балушкина А.А., Тютюнник В.Л., Кан Н.Е., Пустотина О.А., Москалева Г.В. Новые тенденции в профилактике и лечении послеродового мастита и лактостаза. Медицинский совет. 2019;12:136-141. DOI: https://doi.org/10.21518/2079-701X-2019-12-136-141.

Конфликт интересов: авторы заявляют об отсутствии возможных конфликтов интересов.

Финансирование: работа проведена без спонсорской поддержки.

\section{New trends}

\section{IN PREVENTION AND TREATMENT OF POSTPARTUM MASTITIS AND LACTOSTASIS}

\author{
Anna A. BALUSHKINA ${ }^{1}$, Victor L. TYUTYUNNIK ${ }^{1}$, Natalia E. KAN ${ }^{1}$, Olga A. PUSTOTINA ${ }^{2}$, Galina V. MOSKALEVA ${ }^{3}$ \\ ${ }^{1}$ Federal State Budgetary Institution «Kulakov National Medical Research Centre for Obstetrics, Gynaecology and Perinatology» of the \\ Ministry of Health of Russian Federation: 117997, Russia, Moscow, Akademika Oparina St., 4 \\ ${ }^{2}$ Academy of Medical Education named F.I. Inozemtsev: 190013, Russia, St. Petersburg, Moscow Ave, 22, letter M \\ 3 Federal State Budgetary Educational Institution of Higher Education «Yevdokimov Moscow State University of Medicine and Dentistry» \\ of the Ministry of Health of the Russian Federation: 127473, Russia, Moscow, Delegatskaya St., 20, Bldg. 1
}

\section{Author credentials:}

Balushkina Anna Andreevna - Cand. of Sci. (Med.), Researcher of Federal State Budgetary Institution «Kulakov National Medical Research Centre for Obstetrics, Gynaecology and Perinatology» of the Ministry of Health of Russia; tel.: +7 (916) 035-24-71; e-mail:ann.balushkina@gmail.com Tyutyunnik Victor Leonidovich - Dr. of Sci. (Med.), Head of the 1st Obstetric Physiological
Department, Federal State Budgetary Institution «Kulakov National Medical Research Centre for Obstetrics, Gynaecology and Perinatology» of the Ministry of Health of Russia; tel.: +7 (903) 969-50-41; e-mail: tioutiounnik@mail.ru Kan Natalia Enkynovna - Dr. of Sci. (Med.), Professor for Chair for Obstetrics and Gynaecology, Federal State Budgetary Institution
«Kulakov National Medical Research Centre for Obstetrics, Gynaecology and Perinatology» of the Ministry of Health of Russia; Tel.: +7 (926) 220-86-55; e-mail: kan-med@mail.ru Pustotina Olga Anatolevna - MD, Professor of the Department of Obstetrics and Gynecology with a course of reproductive medicine.; tel.: +7 (812) 334-76-50; e-mail: pustotina@gmail. com. ORCID: 0000-0001-6117-7270 
Moskaleva Galina Vladimirovna -

a sixth year student, General Medicine

Faculty, Federal State Budgetary
Educational Institution of Higher

Education «Yevdokimov Moscow State

University of Medicine and Dentistry» of the Ministry of Health of the Russian

Federation; tel.: +7 (903) 623-28-93;

e-mail: g_moskaleva@oparina4.ru

\section{ABSTRACT}

Exclusive breastfeeding in the first 6 months of life is recommended by the World Health Organization, since breast milk provides the baby with all the nutrients and elements necessary for normal development and growth. In the first weeks of lactation, women can often face a number of problems, such as pain in the breasts and nipples, nipple cracks and mastitis. These problems make feeding difficult and, in some cases, lead to the cessation of breastfeeding. Mastitis is a terrible complication of the postpartum period and the basis for the cessation of lactation. Counseling and support of mothers, prevention of lactostasis, nipple cracks and teaching techniques to properly attach the child, reduce the complications of lactation. Timely diagnosis and adequate therapy of mastitis, helps to preserve breastfeeding and improve the health of the mother and child.

Keywords: breastfeeding, lactostasis, postpartum mastitis, lactobacillus

For citing: Balushkina A.A., Tyutyunnik V.L., Kan N.E., Pustotina O.A., Moskaleva G.V. New trends in prevention and treatment of postpartum mastitis and lactostasis.. Meditsinsky Sovet. 2019;12:136-141. DOI: https://doi.org/10.21518/2079-701X-2019-12-136-141.

Conflict of interest: The authors declare no conflict of interest.

Funding: The work was carried out without sponsorship.

ослеродовой (лактационный) мастит (ПМ) - это воспалительное заболевание молочной железы, развивающееся после родов и сопряженное с процессом лактации.

Частота ПМ составляет 0,5-6\% от общего числа родов. Частота гнойного ПМ колеблется от 2 до 11\%. Крайне редко развивается мастит во время беременности (0,1-1\% по отношению ко всем больным маститом) [1, 2]. Официальный уровень заболеваемости может составлять от незначительного количества до 33\% кормящих грудью женщин, однако часто статистический анализ затруднен, так как большинство женщин занимаются самолечением и прибегают к помощи лиц, не имеющих медицинского образования, либо в поздние сроки обращаются для хирургического лечения. У 90\% больных поражается одна молочная железа, причем правосторонний ПМ встречается в 55\%, левосторонний - в 34\%, двусторонний - в 10\% случаев [3].

Мастит наиболее часто встречается на второй и третьей неделе после родов. Большинство авторов указывают, что от 74\% то 95\% случаев наблюдаются в течение первых 12 недель [1, 4, 5]. Однако заболевание может возникнуть в любой период лактации, включая второй год после родов. Абсцесс груди также часто встречается в течение первых 6 недель после родов, однако может встречаться и позже [3, 6].

По данным систематического обзора, изучавшего проблемы грудного вскармливания, было показано, что примерно у 25-30\% женщин в послеродовом периоде имеются проблемы с лактацией, в том числе явления лактостаза в 10,8\% и мастита в 5,6\% [7]. Испытывающие боль при грудном вскармливании женщины самостоятельно отказываются от лактации, что является крайне важной социальной проблемой. Кормящие матери требуют более тщательного наблюдения врачами - акушерами-гинекологами и неонатологами в целях проведения профилактики развития осложнений лактации и предотвращения раннего отказа от кормления. Своевременная терапия и предикция лактостаза и мастита способствуют увеличению продолжительности грудного вскармливания, удовлетворенности матерей, а также более здоровому развитию детей.
Основными возбудителями ПМ считаются Staphylococcus aureus, значительно реже другие микроорганизмы: S. Epidermidis, Streptococcus A и B, Enterobacter spp., Escherichia spp., Pseudomonas aeruginosa, Klebsiella spp. По данным российских авторов, золотистый стафилококк является доминирующим возбудителем в виде монокультуры или в ассоциации с другими патогенными микроорганизмами и высевается до 80\% случаев ПМ [1, 8, 9]. Недавние исследования показали растущую важность S. epidermidis при мастите и выявили, что его частота может быть даже выше, чем у S. aureus [10]. Кроме этого, необходимо помнить, что бактерии часто встречаются в грудном молоке бессимптомно, и спектр этих бактерий часто очень напоминает по своему составу бактерии кожи. Таким образом, присутствие в молоке бактерий не обязательно указывает на наличие инфекции, даже если эти бактерии не попали в молоко с кожи [11].

Независимо от штаммов стафилококка, вызывающих мастит, обычно они проявляют два общих свойства: устойчивость к метициллину и другим антибиотикам и высокую способность образовывать биопленки [12]. Это во многом объясняет, почему мастит трудно поддается антибактериальной терапии и является одной из основных причин прекращения кормления грудью. По данным различных авторов, до 25\% женщин прекратили лактацию по причине мастита [5, 7, 13]. В этой связи перспективным направлением является поиск новых стратегий профилактики и терапии послеродового мастита, а также лактостаза.

В последнее время во всем мире растет понимание того, что данная инфекция не является первичной, а вызывается вследствие лактостаза, предоставляющего благоприятную среду для развития бактерий. Безусловно, неэффективное и неадекватное опорожнение молочных желез при лактостазе, вызванное неправильными приемами грудного вскармливания, способствует инициации заболевания [1, 14]. Однако в представлении многих работников здравоохранения мастит остается синонимом инфекции, и медицинский персонал зачастую советует прекратить грудное вскармливание. 
Таким образом, можно сказать, что двумя основными причинами развития мастита являются лактостаз и инфекция. Лактостаз, как правило, - ведущее звено, которое может сопровождаться или прогрессировать в инфекцию.

Лактостаз возникает при неэффективном выводе молока из молочных желез, эта проблема может возникнуть, если молочные железы переполняются и младенец не беретвсе молоко, секретированное железой. Причинами данного состояния могут быть: неправильное прикладывание ребенка к груди, неэффективное сосание, ограничение частоты или продолжительности кормлений, раздельное пребывание матери и ребенка, а также закупорка молочных протоков. Другие условия, предрасполагающие к развитию лактостаза, включают чрезмерную секрецию молока или кормление грудью близнецов [1, 9, 15].

Важность правильного прикладывания к груди ребенка для эффективного вывода молока безусловна. Неправильное прикладывание как причина неэффективного вывода молока сегодня рассматривается как основной предрасполагающий фактор развития лактостаза и мастита [5]. Грамотное послеродовое консультирование, психологическая поддержка матерей, обучение их техникам грудного вскармливания и сцеживания молочных желез способствует профилактике развития вышеуказанных состояний $[16,17]$.

Развитие трещин сосков или болезненность при кормлении часто встречаются одновременно с маститом. Наиболее распространенной причиной боли и травмы сосков является также неправильное прикладывание к груди. Таким образом, эти два состояния могут частично встречаться вместе, поскольку имеют одно и то же механическое происхождение. Кроме того, боль в соске может привести к отказу от кормления из пораженной груди и, таким образом, предрасполагает к лактостазу и нагрубанию груди. Необходимо помнить и о короткой уздечке языка у младенца, которая будет препятствовать правильному прикладыванию к груди и вызывать воспаление и трещины сосков. Все это также снижает эффективность вывода молока и способствует развитию мастита [4, 5, 14].

Суммируя вышесказанное, инфекционный мастит возникает в тех случаях, когда не проводится лечение лактостаза и преодолевается защита, предоставляемая иммунными факторами молока и воспалительной реакцией организма. В нормальных условиях материнское молоко не является благоприятной средой для развития бактерий, и для того, чтобы развилась инфекция, необходимо наличие условий, препятствующих груди разрушать и выводить бактерии из организма. Естественное направление потока молока по молочным протокам при эффективном выводе должно вымывать все микроорганизмы из груди. Неэффективный вывод молока, вызывающий скопление молока, создает благоприятные условия для развития бактерий и, как следствие, инфекции $[13,15]$.

Единой классификации послеродового мастита нет. Согласно МКБ-10, различают:

091.0 Инфекцию соска, связанную с деторождением. Абсиесс соска:

- Во время беременности;

- В послеродовом периоде.
091.1 Абсиесс молочной железы, связанный с деторождением Абсцесс молочной железы

Гнойный мастит

Субареолярный абсцесс

091.2 Негнойный мастит, связанный с деторождением

Лимфангиит молочной железы

Мастит (БДУ, интерстициальный, паренхиматозный)

В клинической практике в зависимости от особенностей течения заболевания выделяют:

патологический лактостаз;

- серозный мастит;

- инфильтративный мастит;

- гнойный мастит: инфильтративно-гнойный (диффузный, узловой), абсцедирующий (фурункул ареолы, абсцесс в толще железы, ретромаммарный абсцесс), флегмонозный (гнойно-некротический), гангренозный [1, 8, 9].

Предрасполагающими факторами к возникновению ПМ являются: лактостаз; трещины сосков; аномалии развития сосков (плоские, втянутые, добавочные); структурные изменения молочных желез (мастопатия, добавочные доли, большие размеры молочных желез, рубцовые изменения); гнойный мастит в анамнезе; снижение иммунной реактивности организма; пластика молочных желез; гипер- и гипогалактия; нарушение гигиены и правил грудного вскармливания [2-4].

В исследовании P. Mediano и соавт. [18] были подтверждены как известные факторы риска (семейные случаи мастита, мастит в предыдущих родах, трещины и инфекции сосков, лактостаз), так и выявлены новые интересные факторы, связанные с повышенным риском инфекционного мастита. Среди них чаще встречались у матерей с маститом: родоразрешение путем кесарева сечения, антибиотикотерапия в родах, послеродовом периоде, применение эпидуральной анальгезии, анемия. Антибиотикотерапия оказалась наиболее сильным фактором риска мастита, поскольку она индуцирует отбор антибиотикорезистентных бактерий в молочной железе и элиминацию потенциальных конкурентов. Антибиотики также влияют на микрофлору влагалища и кишечника матери и развитие кишечной микрофлоры ребенка. В связи с вышеуказанным все случаи назначения антибактериальных препаратов в послеродовом периоде должны быть четко обоснованными.

Диагностика послеродового мастита и лактостаза в большинстве случаев устанавливается на основании жалоб, осмотра, результатов клинико-лабораторного обследования, бактериологического исследования молока, УЗИ молочных желез.

Патологический лактостаз развивается на 2-6-е сутки лактации. Общее самочувствие изменяется мало. Температура тела $-38-38,5^{\circ} \mathrm{C}$. Наблюдается равномерное нагрубание и болезненность молочных желез при пальпации. Без стадии патологического лактостаза мастит развивается редко, но между лактостазом и первыми проявлениями серозного мастита может пройти от 8 до 30 дней.

ПМ преимущественно возникает у первобеременных женщин, в возрастной группе 30 и более лет. Чаще всего в процесс вовлекается наружный квадрат железы, в дальнейшем воспаление может ограничиться первичной 
топографией или распространиться на другие участки молочной железы $[1,4,8]$.

Мастит, как правило, начинается остро и характеризуется: повышением температуры тела (38 ${ }^{\circ} \mathrm{C}$ и выше) с ознобом или без него; ухудшением общего состояния (головная боль, слабость); появлением болей в молочной железе, особенно при кормлении и сцеживании; явлениями лактостаза, увеличением молочной железы в объеме; появлением уплотнений в различных участках молочной железы: при серозном мастите без четких контуров, при инфильтративном - плотный инфильтрат с четкими контурами, при гнойном мастите - плотный с четкими контурами (границами) инфильтрат с участками размягчения, с выраженным отеком тканей над очагом воспаления; гиперемией кожных покровов железы в области поражения; увеличением регионарных подмышечных лимфатических узлов; затрудненным опорожнением молочной железы при сцеживании.

При запоздалом и неэффективном лечении серозная форма ПМ в течение 1-3 дней переходит в инфильтративную, которая продолжается в течение 5-10 дней. Если инфильтрат не рассасывается, обычно происходит его нагноение. Преобладающей формой ПМ является инфильтративно-гнойный мастит (у 2/3 больных), который может протекать в виде диффузной и узловой формы.

Для диффузной формы (более частой) характерно наличие выраженного плотного инфильтрата с пропитыванием тканей гноем (наподобие пчелиных сот) без явного абсцедирования.
При узловой форме образуется небольшой изолированный округлый инфильтрат без признаков абсцедирования. Эту форму заболевания можно отнести к стертой, так как самочувствие и состояние больной не изменены, а клинические и гематологические изменения не характерны для гнойного мастита.

Второй по частоте является абсцедирующая форма гнойного ПМ - фурункулез ареолы, абсцесс ареолы, абсцессы в толще и позади молочной железы. Наиболее тяжелая форма - флегмонозный мастит, при котором возможна генерализация инфекции с переходом в сепсис. При флегмонозном мастите имеется обширное диффузное гнойное поражение молочной железы, течение заболевания тяжелое. Наблюдаются повторные ознобы с повышением температуры тела до $40{ }^{\circ} \mathrm{C}$. Молочная железа значительно увеличена в объеме; болезненна; кожа отечная, гиперемированная с синюшным оттенком.

В современных условиях, наряду с типичной клинической картиной ПМ, встречаются стертые формы заболевания, характеризующиеся невыраженными симптомами, несоответствием между клиническими проявлениями заболевания и тяжестью патологического процесса, что обуславливает в ряде случаев позднюю обращаемость, несвоевременную диагностику и запоздалую терапию [6, 7].

Основными принципами лечения мастита являются: - продолжение грудного вскармливания и поддерживающее консультирование;

- своевременное регулярное сцеживание молока;
ЛАКТАНЗА ${ }^{\circledR}$

ЕСТЕСТВЕННАЯ ЗАЩИТА ОТ ЛАКТОСТАЗА И МАСТИТА С ДВОЙНОЙ ПОЛЬЗОЙ ДЛЯ МАМЫ И МАЛЫША

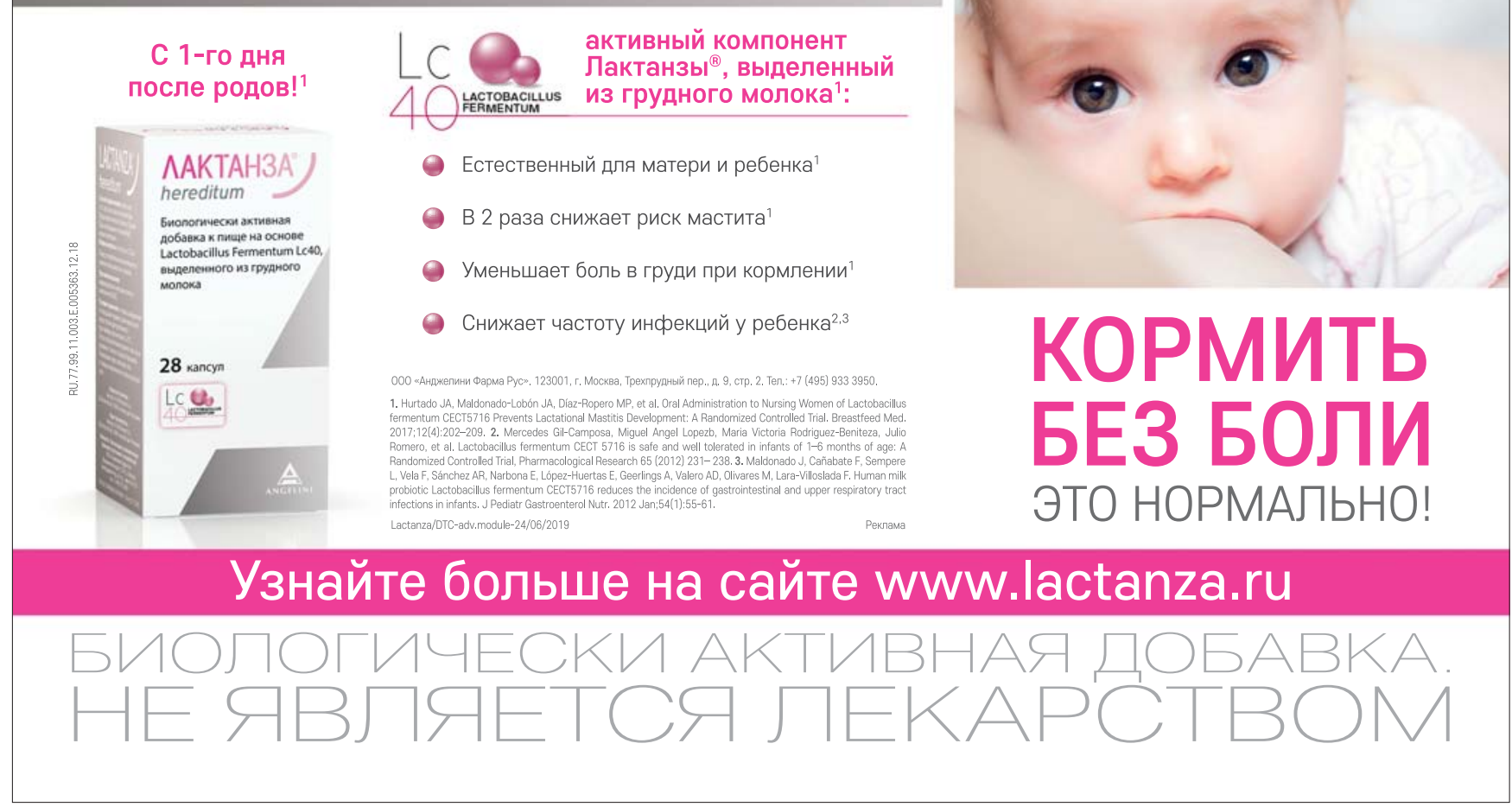


элиминация возбудителя (антибактериальная терапия);

лечение трещин сосков;

- раннее начало лечения;

- проведение лечения с учетом формы и фазы процесса.

В прошлом подавление лактации часто было включено в ведение лактостаза и мастита $[1,9]$. В настоящее время предпочтение отдается поддержанию лактации, так как продолжение грудного вскармливания и регулярное сцеживание способствуют уменьшению застоя молока, элиминации микроорганизмов и продуктов их жизнедеятельности.

До начала лечения и после окончания антибактериальной терапии необходимо проводить бактериологическое исследование молока и отделяемого из молочной железы с определением чувствительности выделенной микрофлоры к антибиотикам. Проведение только консервативной терапии возможно при наличии лактостаза, серозного и инфильтративного мастита.

Лечение может проводиться как в амбулаторных условиях, так и в стационаре в зависимости от состояния пациентки. Системные признаки должны быть ограничены лихорадкой и умеренным недомоганием. В случае амбулаторного лечения повторный осмотр и оценка состояния пациентки обязательны в течение 24-48 часов. Если отсутствует положительная динамика, женщина должна быть госпитализирована.

Учитывая высокую антибиотикорезистентность основных возбудителей мастита, в последнее время проводилось достаточное количество исследований, посвященных оптимизации терапии данной патологии. Одним из перспективных направлений явилось использование пробиотиков для лечения мастита, так как было показано наличие в грудном молоке высокого уровня штаммов лактобактерий.

В 2003 году было впервые описано присутствие физиологической микробиоты в человеческом молоке [19]. По данным зарубежных авторов, из грудного молока здоровых матерей были выявлены штаммы лактобацилл, относящиеся к видам Lactobacillus gasseri, L. fermentum и L. salivarius. Пробиотический потенциал данных бактерий крайне высок [20].

Проведенные ранее исследования показали, что мастит и болезненность при грудном вскармливании характеризуются бактериальным дисбиозом - процессом, при котором популяция возможных патогенов растет за счет снижения нормальной микробиоты молочных желез [21, 22].

Кроме этого, была показана способность отдельных пробиотических штаммов восстанавливать баланс микробиоты в человеческом молоке за счет снижения бактериальной нагрузки, связанной с маститом. В этих исследованиях были представлены доказательства возможности эффективного решения проблемы мастита с помощью пробиотических бактерий [10, 22, 23].

Одним из пробиотических штаммов, выделенных из грудного молока здоровых женщин, является Lactobacillus fermentum CECT5716 [20, 24]. Этот штамм также способен колонизировать молочную железу при его пероральном введении кормящим грудью матерям в капсулах [23]. L. fermentum способен колонизировать кишечник человека, обладает высоким уровнем безопасности, противо- инфекционными и иммуномодулирующими свойствами [24-26]. Кроме того, в ходе РКИ у взрослых субъектов было доказано, что L. fermentum может снижать частоту эпизодов, связанных с гриппом, при его введении до и после вакцинации [27].

В дальнейшем исследователями была проведена оценка эффективности перорально вводимых штаммов лактобацилл, выделенных из грудного молока, в качестве лечения инфекционного мастита во время лактации, и было выявлено, что L. salivarius CECT5713 и L. gasseri CECT5714 представляются эффективной альтернативой антибиотикам в лечении инфекционного мастита $[10,11,28]$.

В других работах также была выявлена высокая эффективность применения пробиотиков, в частности L. fermentum CECT5716, по сравнению с антибактериальной терапией инфекционного мастита при лактации, и было продемонстрировано снижение нагрузки стафилококками в грудном молоке [22, 23].

В исследовании эффективности пробиотического штамма L. salivarius PS2 была отбрана группа женщин с маститом в анамнезе. Авторами отмечено выраженное снижение частоты возникновения послеродового мастита в группе пациенток, получавших пробиотик [28].

В рандомизируемом контролируемом исследовании Hurtado J.A. и соавт. [29] была проведена оценка профилактического эффекта перорального приема Lactobacillus fermentum СЕСТ5716 в отношении частоты мастита у кормящих женщин в течение первых 4 месяцев лактации. Авторами было показано, что прием препарата снизил стафилококковую нагрузку у кормящих и частоту возникновения клинического мастита на 51\%. Кроме того, в исследовании путем идентификации с помощью MALDITOF масс-спектрометрии было подтверждено, что препарат, содержащий L. fermentum, действительно проходил в грудное молоко.

Кроме этого, изучены положительные стороны применения L. fermentum CECT5716 у детей первого и второго полугодия жизни. По данным рандомизированного двойного слепого контролируемого исследования, у детей, получающих смесь с Lactobacillus fermentum СЕСТ5716, значительно снижается частота инфекций желудочно-кишечного и респираторного тракта [30, 31].

Таким образом, в результате многочисленных исследований определены следующие положительные эффекты применения Lactobacillus fermentum CECT5716 при грудном вскармливании:

1. Применение при первых симптомах боли во время грудного вскармливания способствует снижению болевых ощущений, что благоприятствует поддержанию грудного вскармливания, так как боль в молочной железе является основной причиной преждевременного и нежелательного отказа от кормления грудью.

2. Профилактическое применение способствует снижению риска развития мастита. Снижая концентрацию патогенных бактерий во флоре молочной железы и способствуя восстановлению баланса микрофлоры, препарат делает грудное вскармливание более удобным и здоровым. 
3. Применение при остром мастите способствует уменьшению частоты рецидивов мастита. Может использоваться с целью восстановления микрофлоры молочной железы (в том числе после применения антибиотиков), предотвращая повторное возникновение заболевания. Штамм Lactobacillus fermentum Lc40 (CECT5716) имеет естественное происхождение и полностью соответствует критериям безопасности пробиотиков, включен в список таксономических единиц, предлагаемых Европейским управлением по контролю за качеством продуктов питания (EFSA). Данная сертификация присваивается тем штаммам, которые, согласно их истории использования у населения, обладают гарантиями безопасности, не нуждаясь в проведении дополнительных исследований для подтверждения этой безопасности. На российском рынке препарат, содержащий L. fermentum CECT5716, зарегистрирован как
Лактанза, показанием к применению данного препарата является профилактика и лечение инфекционного мастита, а также лактостаза у кормящих женщин.

Необходимо помнить, что главными методами, способствующими снижению лактостаза и распространению инфекции, являются улучшение практики грудного вскармливания, включая ранний тесный контакт матери и новорожденного, совместное их размещение, оказание квалифицированной помощи с целью обеспечения правильного прикладывания ребенка к груди, а также неограниченное и исключительное грудное вскармливание, а прием пробиотиков является новой эффективной стратегией лечения и профилактики указанных состояний, способствующей сохранению грудного вскармливания и улучшению здоровья матери и ребенка.

Поступила/Received 21.05.2019

\section{ЛИTEPATYPA/REFERENCES}

1. Орджоникидзе Н.В., Емельянова А.И., Мешалкина И.В. Послеродовая инфекция. Под ред. акад. РАМН, Сухих Г.Т. М., 2012. 480 с. [Ordzhonikidze N.V., Emelyanova A.I., Meshalkina I.V. Postpartum infection, under the editorship of Acad. of RAMS, Sukhikh G.T. M., 2012. 480 p.] (In Russ).

2. World Health Organization. Postnatal care for mothers and newborns: Highlights from the World Health Organization 2013 Guidelines. [Accessed on: 01 Ekim 2016]. Available at: http://www.who.int/maternal_child_adolescent/ publications/WHO-MCA-PNC-2014-Briefer A4.pdf

3. Рюмина И.И., Тютюнник В.Л., Кан Н.Е., Зубков B.В. Экзема и трещины сосков у кормящих матерей: профилактика и лечение. Акушерство и гинекология. 2014;8:122-126. [Ryumina I.I., Tyutyunnik V.L., Kan N.E., Zubkov V.V. Eczema and nipple cracks in breastfeeding mothers: prevention and treatment. Akusherstvo i Ginekologiya. 2014;8:122-126] (In Russ).

4. Bellù R., Condò M. Breastfeeding promotion: evidence and problems. Pediatr Med Chir. 2017;39(2):156.

5. Contreras G.A., Rodriguez J.M. Mastitis: Comparative etiology and epidemiology. J Mammary Gland Biol Neoplasia 2011;16:339-356.

6. Пустотина О.А. Лактационный мастит: теория и практика медицинской помощи. По материалам лечения 642 родильниц с маститом под руководством Б.Л. Гуртового. Российский вестник акушера-гинеколога. 2013;5:105-108. [Pustotina O.A. Lactational mastitis: the theory and practice of medical care. A case study of treatment of 642 puerperas with mastitis under the guidance of B.L. Gurtovoy. Rossiysky Vestnik Akushera-Ginekologa. 2013;5:105-108.] (In Russ).

7. Karaçam Z., Sağlık M. Breastfeeding problems and interventions performed on problems: systematic review based on studies made in Turkey. Turk Pediatri Ars. 2018;53(3):134-148.

8. Воеводин С.М., Шеманаева Т.В. Лактационный мастит. Методы лечения и профилактики. Акушерство и гинекология. 2015;5:101-103. [Voevodin S.M., Shemanaeva T.V. Lactational mastitis. Methods of treatment and prevention. Akusherstvo i Ginekologiya. 2015;5:101-103.] (In Russ).

9. Руководство по амбулаторно-поликлинической помощи в акушерстве и гинекологии. Под ред. В.Н. Серова, Г.Т. Сухих, В.Н. Прилепской, В.Е. Радзинского. 3-е изд., перераб. и доп. М.: ГЭОТАР-Медиа, 2016. 1136 с. [Guidelines for outpatient care in obstetrics and gy- necology. Under the editorship of V.N. Serov, G.T. Sukhikh, V.N. Prilepskaya, V.E. Radzinsky. 3rd ed., revised and enlarged. M.: GEOTAR-Media, 2016. 1136 p.] (In Russ).

10. Jimenez E., Fernandez L., Maldonado A et al. Oral administration of Lactobacillus strains isolated from breast milk as an alternative for the treatment of infectious mastitis during lactation. Appl Environ Microbiol 2008;74:4650-55.

11. Popova B., Mitev D., Nikolov A. The role of mother's milk and breast feeding. medical problems during the lactation period lactobacilus fermentum - a new approach towards the prevention and the treatment of acute and subacute mastitis. Akush Ginekol (Sofiia). 2016;55(3):47-52.

12. Delgado S., Arroyo R., Jimeinez E. et al. Staphylococcus epidermidis strains isolated from breast milk of women suffering infectious mastitis: Potential virulence traits and resistance to antibiotics. BMC Microbiol 2009;9:82.

13. Branch-Elliman W., Golen T.H., Gold H.S. et al. Risk factors for Staphylococcus aureus postpartum breast abscess. Clin Infect Dis. 2012;54(1):71-7.

14. WHO. Indicators for assessing infant and young child feeding practices. Part I: definition. Geneva, Switzerland: World Health Organization; 2008.

15. Яковлев Я.Я., Манеров Ф.К. Оценка факторов риска лактостаза и лактационного мастита. Сибирское медицинское обозрение. 2015;1:6772. [Yakovlev Y.Ya., Manerov F.K. Evaluation of risk factors for lactostasis and lactational mastitis. Sibirskoye Meditsinskoye Obozrenie. 2015;1:67-72.] (In Russ).

16. Lumbiganon P., Martis R., Laopaiboon M. et al. Antenatal breastfeeding education for increasing breastfeeding duration. Cochrane Database Syst Rev 2016;12:CD006425.

17. McFadden A., Gavine A., Renfrew M.J. et al. Support for healthy breastfeeding mothers with healthly term babies (Review). Cochrane Database Syst Rev 2017;2:CD001141.

18. Mediano P., Fernandez L., Rodriguez J.M. et al. Case-control study of risk factors for infectious mastitis in Spanish breastfeeding women. BMC Pregnancy Childbirth 2014;14:195.

19. Martin R., Langa S., Reviriego C. et al. Human milk is a source of lactic acid bacteria for the infant gut. J Pediatr 2003;143:754-58.

20. Martin R., Olivares M., Marin M.L. et al. Probiotic potential of 3 lactobacilli strains isolated from human breast milk. J Hum Lact 2005;21:8-17.
21. Fernandez L., Arroyo R., Espinosa I. et al. Probiotics for human lactational mastitis. Benef Microbes 2014;5:169-83.

22. Maldonado-Lobon J.A., Diaz-Lopez M.A., Carputo R. et al. Lactobacillus fermentum CECT 5716 reduces Staphylococcus load in the breastmilk of lactating mothers suffering breast pain: A randomized controlled trial. Breastfeed Med 2015;10:425-32.

23. Arroyo R., Martin V., Maldonado A. et al. Treatment of infectious mastitis during lactation: Antibiotics versus oral administration of Lactobacilli isolated from breast milk. Clin Infect Dis 2010;50:1551-58.

24. Olivares M., Diaz-Ropero M.P., Martin R. et al. Anti- microbial potential of four Lactobacillus strains isolated from breast milk. J Appl Microbiol 2006;101:72-79.

25. Díaz-Ropero M.P., Martín R., Sierra S. et al. Two Lactobacillus strains, isolated from breast milk, differently modulate the immune response.J Appl Microbiol 2007;102:337-43.

26. Cárdenas N., Laiño J.E., Delgado S. et al. Relationships between the genome and some phenotypical properties of Lactobacillus fermentum CECT 5716, a probiotic strain isolated from human milk. Appl Microbiol Biotechnol. 2015;99(10):4343-53.

27. Olivares M., Díaz-Ropero M.P., Sierra S. et al. Oral intake of Lactobacillus fermentum CECT5716 enhances the effects of influenza vaccination. Nutrition 2007; 23:254-60

28. Fernandez L., Cárdenas N., Arroyo R. et al. Prevention of infectious mastitis by oral administration of Lactobacillus salivarius PS2 during late pregnancy. Clin Infect Dis 2016;62:568-73.

29. Hurtado J.A., Maldonado-Lobón J.A., Díaz-Ropero M.P. et al. Oral Administration to Nursing Women of Lactobacillus fermentum CECT5716 Prevents Lactational Mastitis Development: A Randomized Controlled Trial. Breastfeed Med. 2017;12(4):202-209.

30. Gil-Campos M., López M.Á., Rodriguez-Benítez M.V. et al. Lactobacillus fermentum CECT 5716 is safe and well tolerated in infants of 1-6 months of age: a randomized controlled trial. Pharmacol Res. 2012;65(2):231-8.

31. Maldonado J., Cañabate F., Sempere L. et al. Human milk probiotic Lactobacillus fermentum CECT5716 reduces the incidence of gastrointestinal and upper respiratory tract infections in infants. J Pediatr Gastroenterol Nutr. 2012;54(1):55-61. doi: 10.1097/ MPG.0b013e3182333f18. 